\title{
Memorial de Paine: Un lugar para la memoria. «Recuerdo de las Ausencias»
}

Un único gesto, extendido sobre el terreno, colma el lugar y lo esculpe dándole una nueva topografía. El sitio se convierte en un espacio y en una escultura, que reconoce el paisaje natural del sembradío y lo ordena como una metáfora a un gran bosque artificial, en el que la siembra es el camino y ondula en el viento.

A partir de una trama ortogonal de módulos de $1,50 \mathrm{~m}$, se erigen 1.000 pilares de madera impregnada, que conforman la trama espacial del Memorial. Se han retirado 70 pilares de madera para generar los espacios de la ausencia: vacíos de $3 \times 3 \mathrm{~m}$, abiertos al cielo, que evocan a cada uno de los 70 hombres desaparecidos.

Los 8 pilares de madera que delimitan estos espacios llevarán intervenciones escultóricas en sus remates, y podrán ser intervenidos libremente con palabras, dibujos, tallados, etc. El suelo de cada ausencia será construido por los familiares y amigos de las víctimas, a través de un mosaico de cerámicas con asesoría de arquitectos y artistas. En cada uno de estos lugares, la intervención y participación de todos es clave en su definición espacial.

En el corazón del conjunto, un ágora central de $12 \times 12 \mathrm{~m}$ es el espacio que recoge el encuentro y las conmemoraciones. Treinta y dos pilares de madera de $12 \mathrm{~m}$ de alto dibujan el límite virtual de su perímetro, y evocan los conceptos de unidad y fortaleza.

El pavimento de toda la zona peatonal restante será de conchuela blanca para reflejar la luz y dar sonido a los pasos, para hacer más conscientes y dramáticos los silencios en los espacios conmemorativos. El caminar, como una acción simbólica e individual, transcurre al interior de este sembradío artificial, para encontrar y descubrir los espacios de la ausencia, para detenerse en los lugares vacíos.

La zanja de regadío evita las rejas y resguarda el perímetro. El acceso por la calzada poniente y en la medianera del terreno, permite funcionalidad de entradas, salidas, estacionamientos y servicios sin interferir con el espacio del Memorial. Esta intervención no pasa inadvertida, con un gesto radical y rotundo transforma todo el sitio en proyecto, todo el lugar en una escultura. Desde lo lejano es una señal inequívoca de fuerza, voluntad y unidad, y en su interior ofrece el recogimiento individual y el encuentro colectivo en una permanente conmemoración.

Setenta campesinos detenidos, setenta hombres de campo desaparecidos están aquí, en setenta ausencias, recipientes de vacío y silencio definidos por altos postes de madera, intervenidos en forma escultórica y también espontánea. Sus nombres no resbalarán de la madera, no se irán jamás de nuestra memoria.

\section{Ficha técnica}

Proyecto:

Memorial de Paine.

Mandante:

Concurso de Arquitectura

Ministerio de Obras Públicas.

Arquitectura:

Iglesis-Prat Arquitectos

Jorge Iglesis $\mathrm{G}$.

Leopoldo Prat V.
Arquitecto coordinador: Rossana Pecchi D.

Arquitecto colaborador: Marcos Contreras.

Escultora:

Alejandra Ruddoff B.

Cálculo estructural: RG Ingenieros.

Ubicación:

Cruce camino 18 de Septiembre con Ramal de Enlace a Paine, Comuna de Paine.

Materialidad:

Postes de eucalipto impregnado de 8" de diámetro de distintas alturas, pavimentos de maicillo y conchuela marina blanca. Mosaicos de cerámica sobre base de hormigón.

Costo de construcción: $\$ 60.000 \times \mathrm{m}^{2}$

Superficie terreno: $2.500 \mathrm{~m}^{2}$.

Área libre circulación: $700 \mathrm{~m}^{2}$.

Área memorial: $1.800 \mathrm{~m}^{2}$.

Año: 2007. 


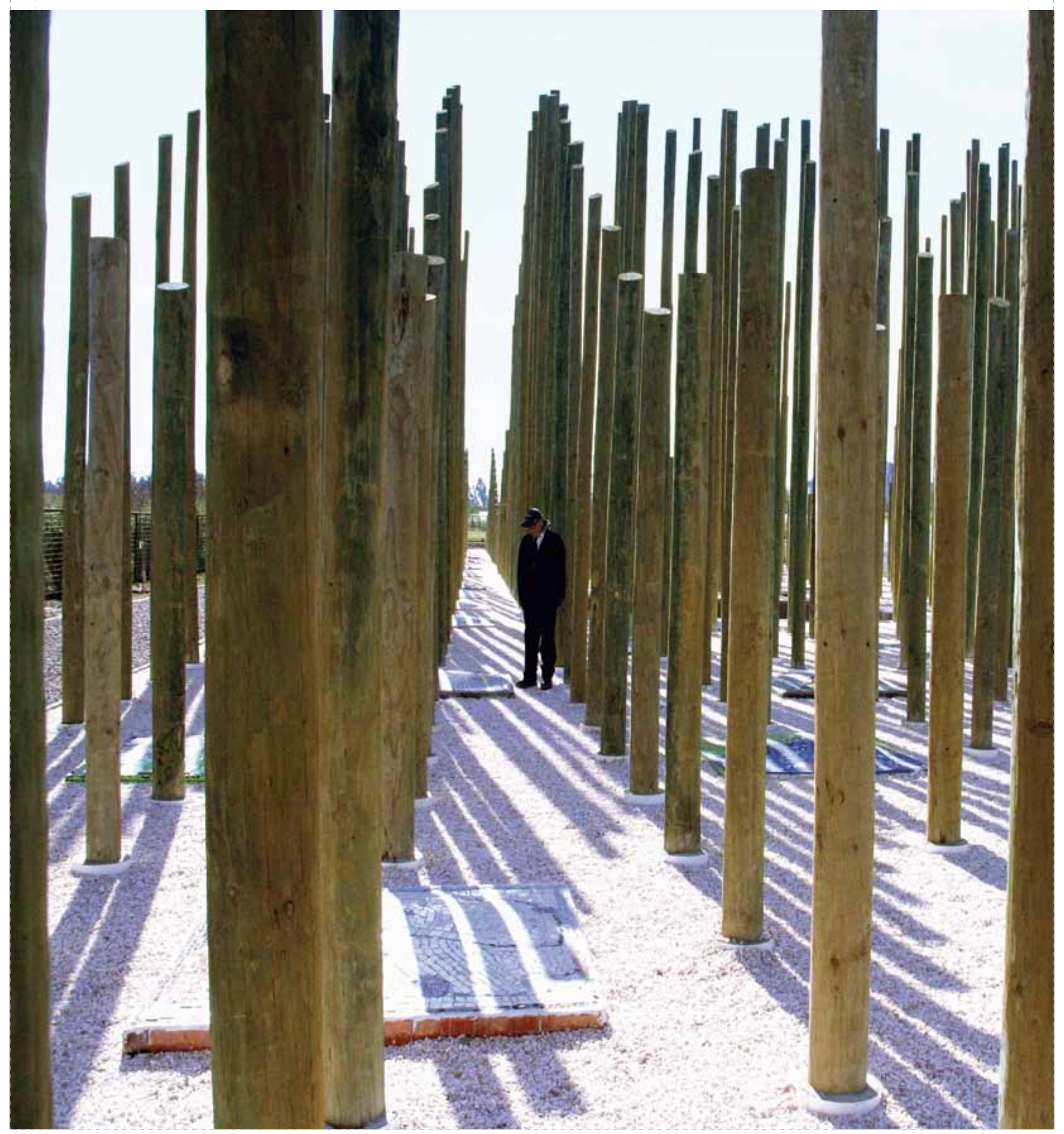




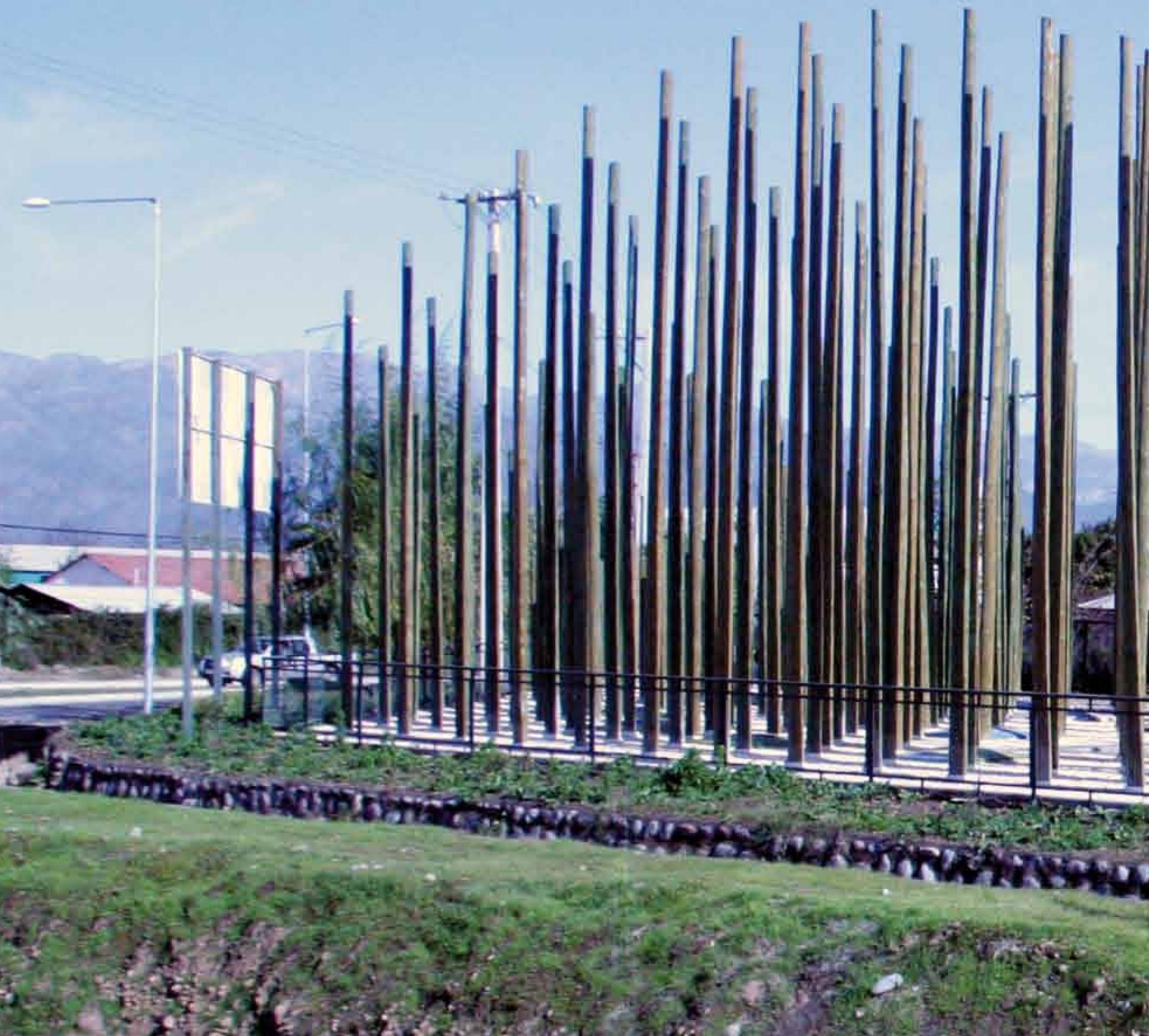




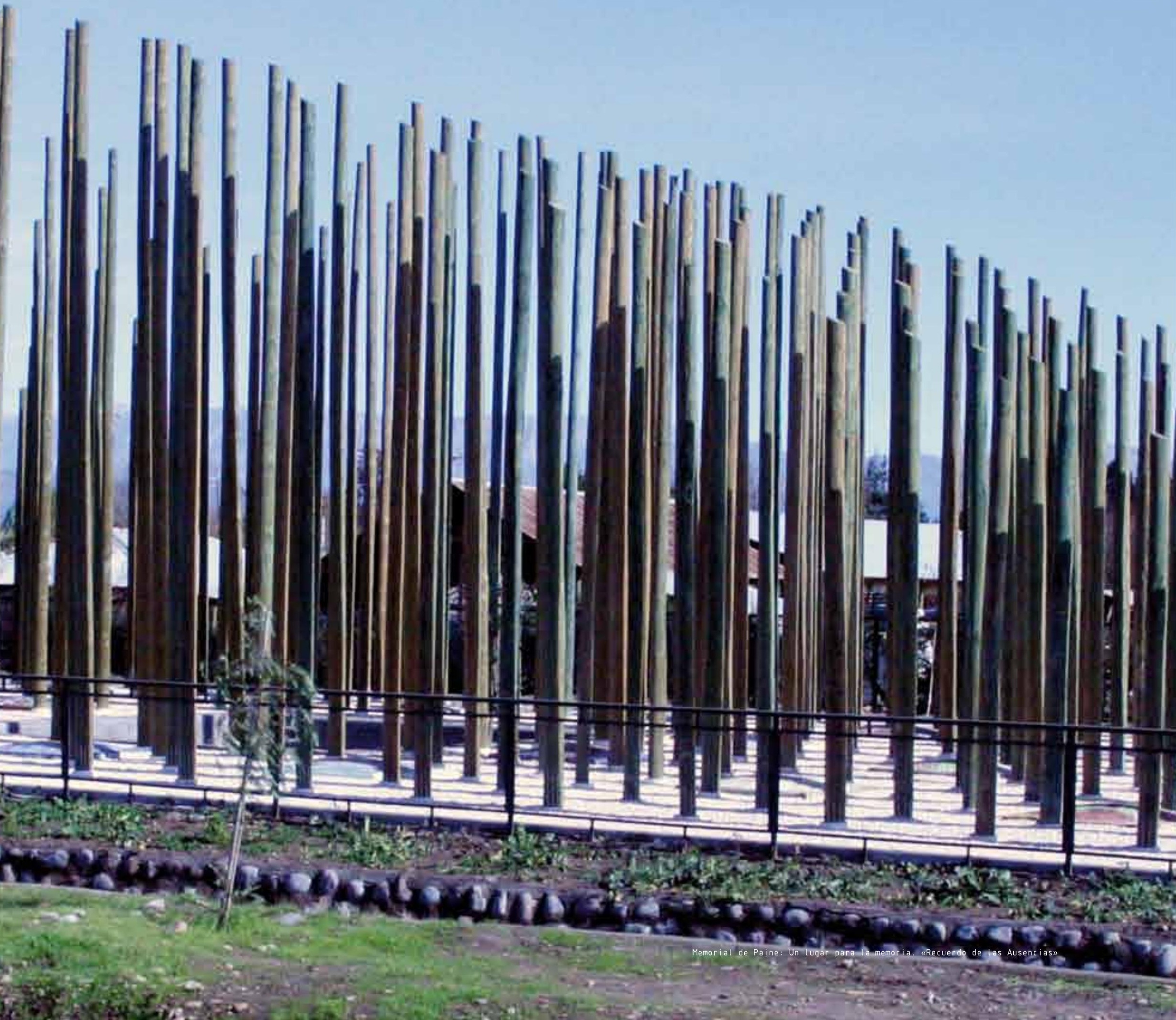




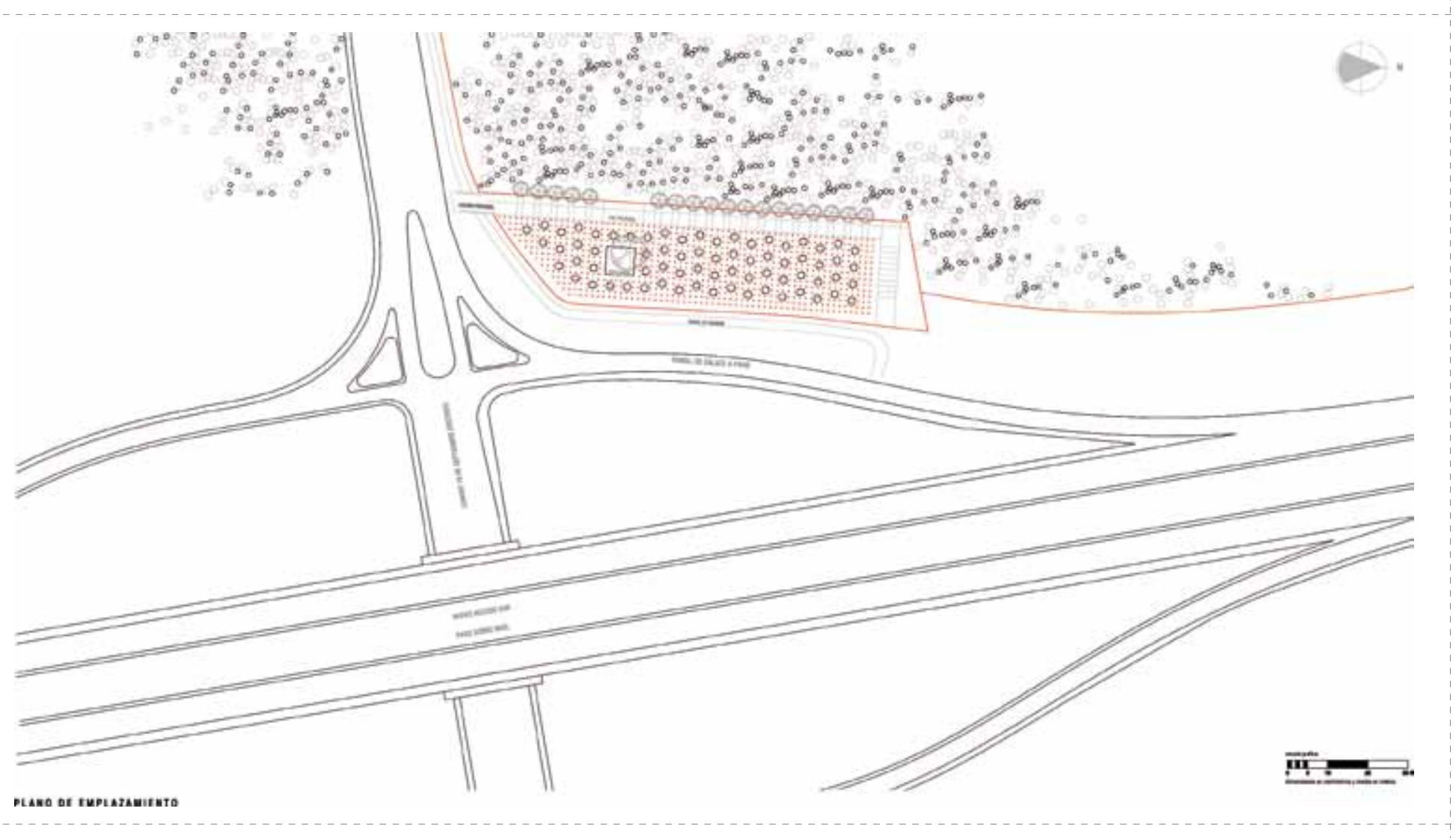

El pisocanta al caun may te, el somido de ansencia commenuraba con il silencio en caba

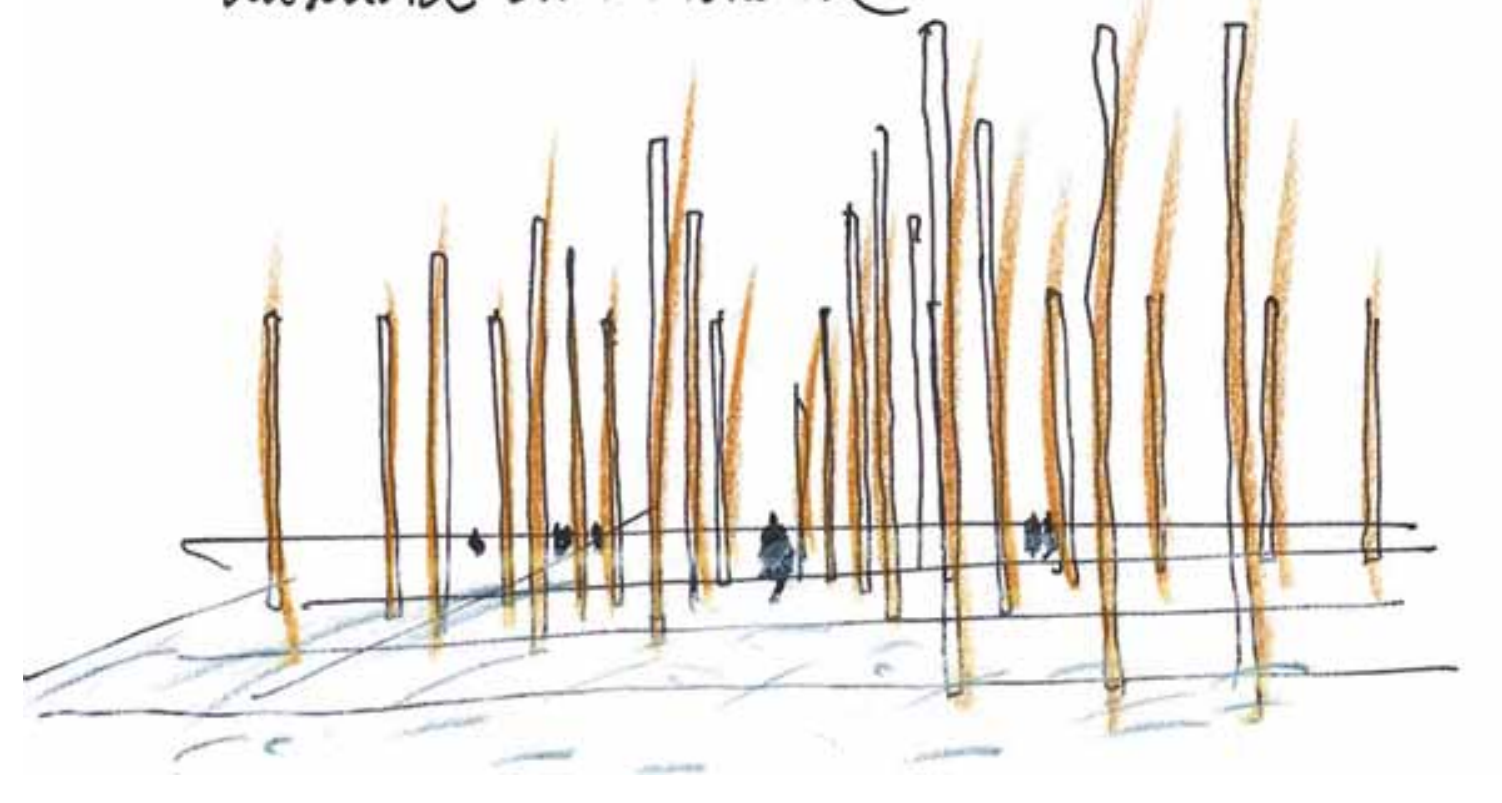




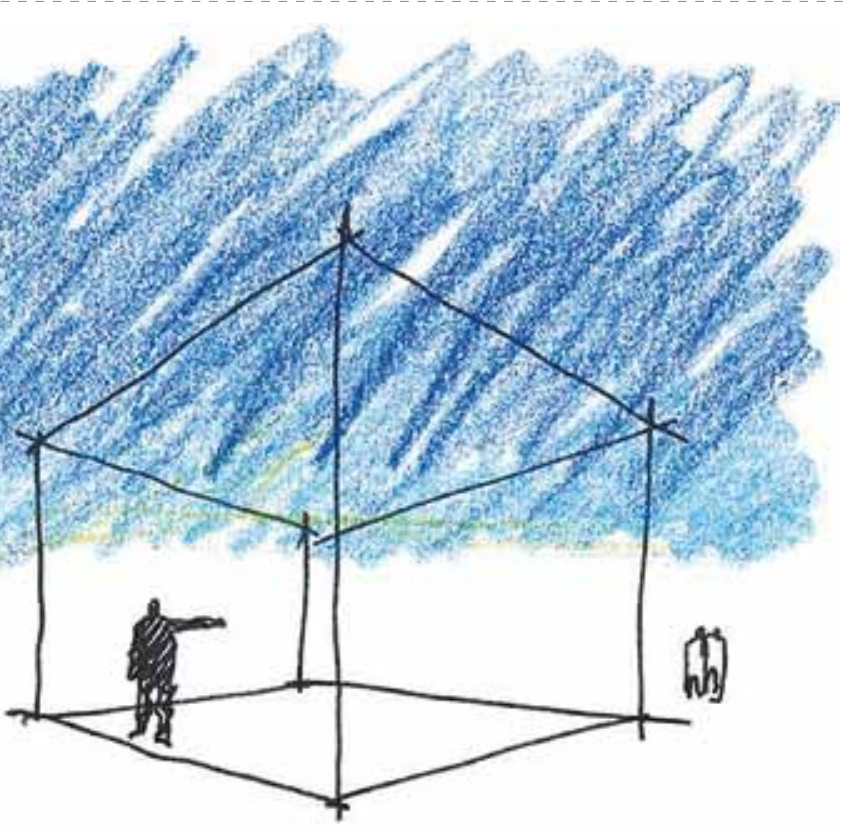

El luzar de commemoracin de la ansencia. Aqui stam los que ya no stam

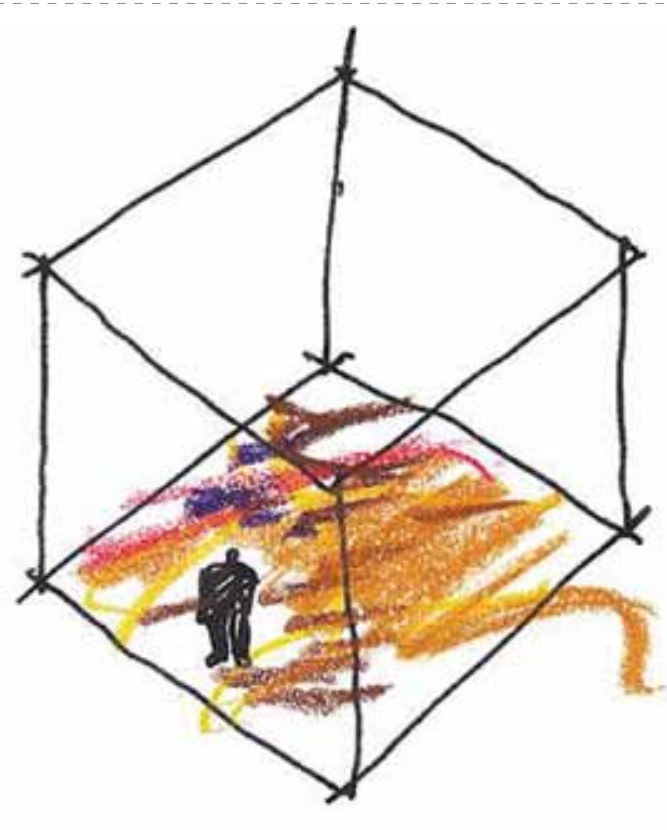

El priso de cabla ansencia seraconstrinido fos la familia. Ien mosaico de chlo, de lur y esferanza

thraciou stntak onithrt

ELEvacion oemeral rosiente 


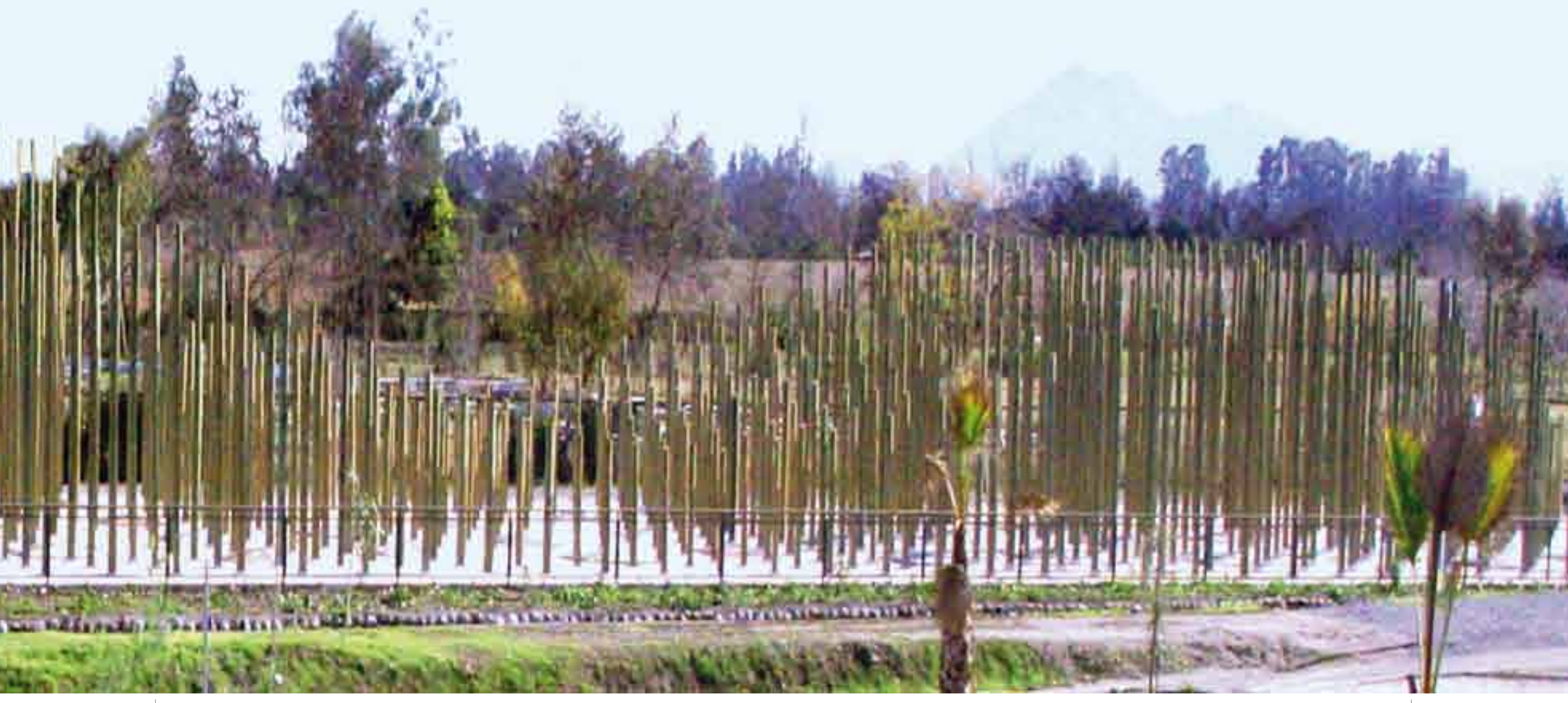




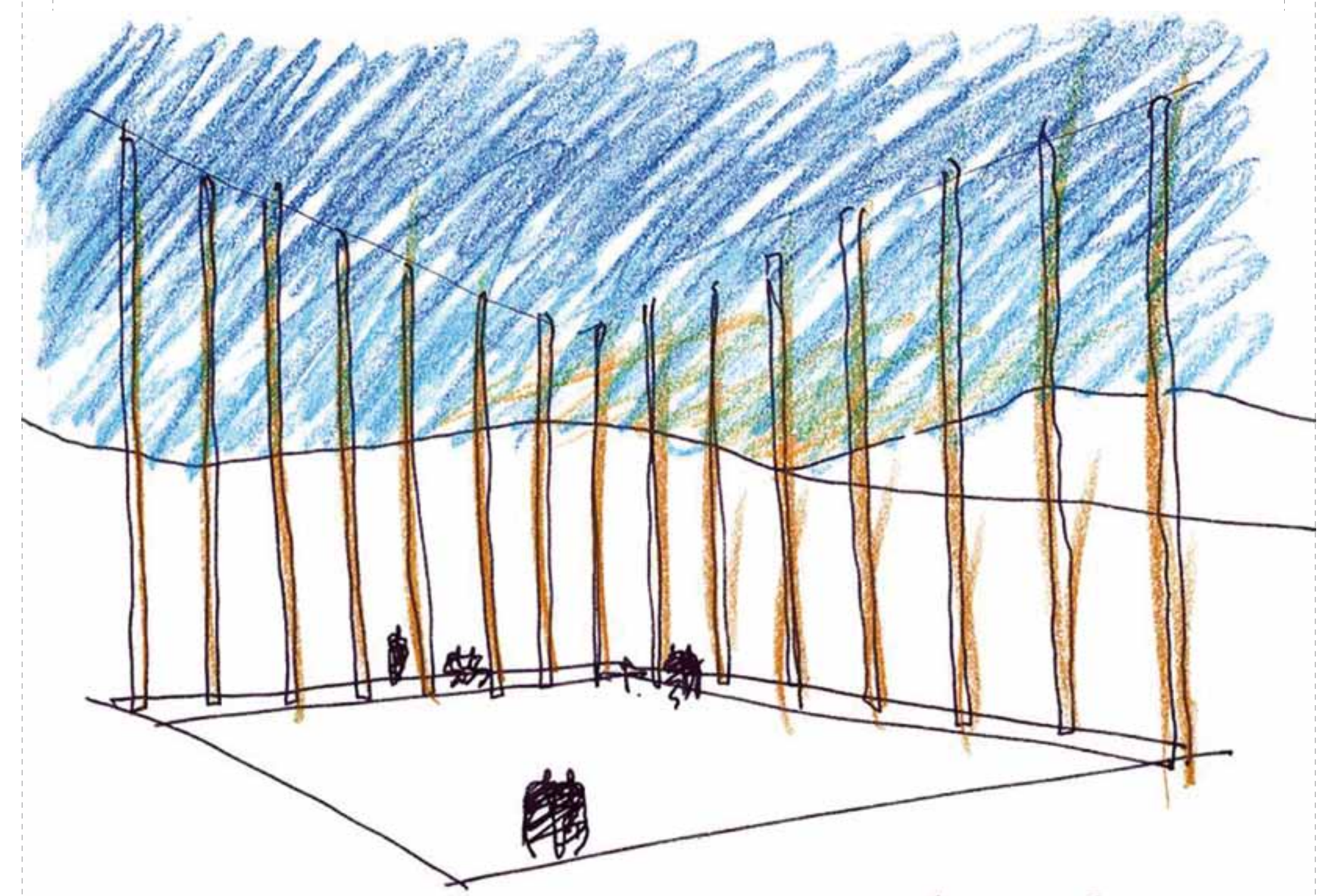

Evel agra centrel los modern intervenidy

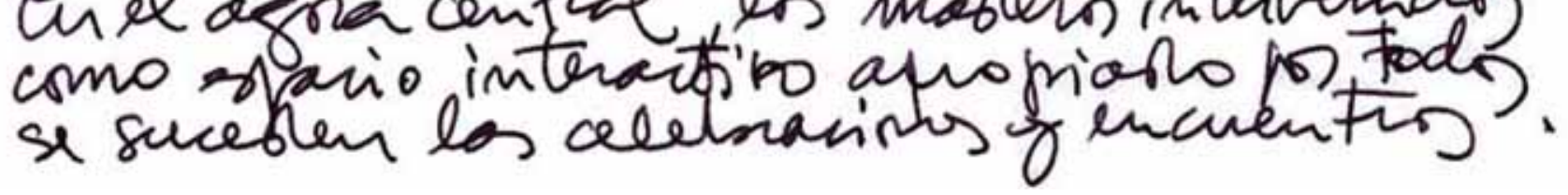




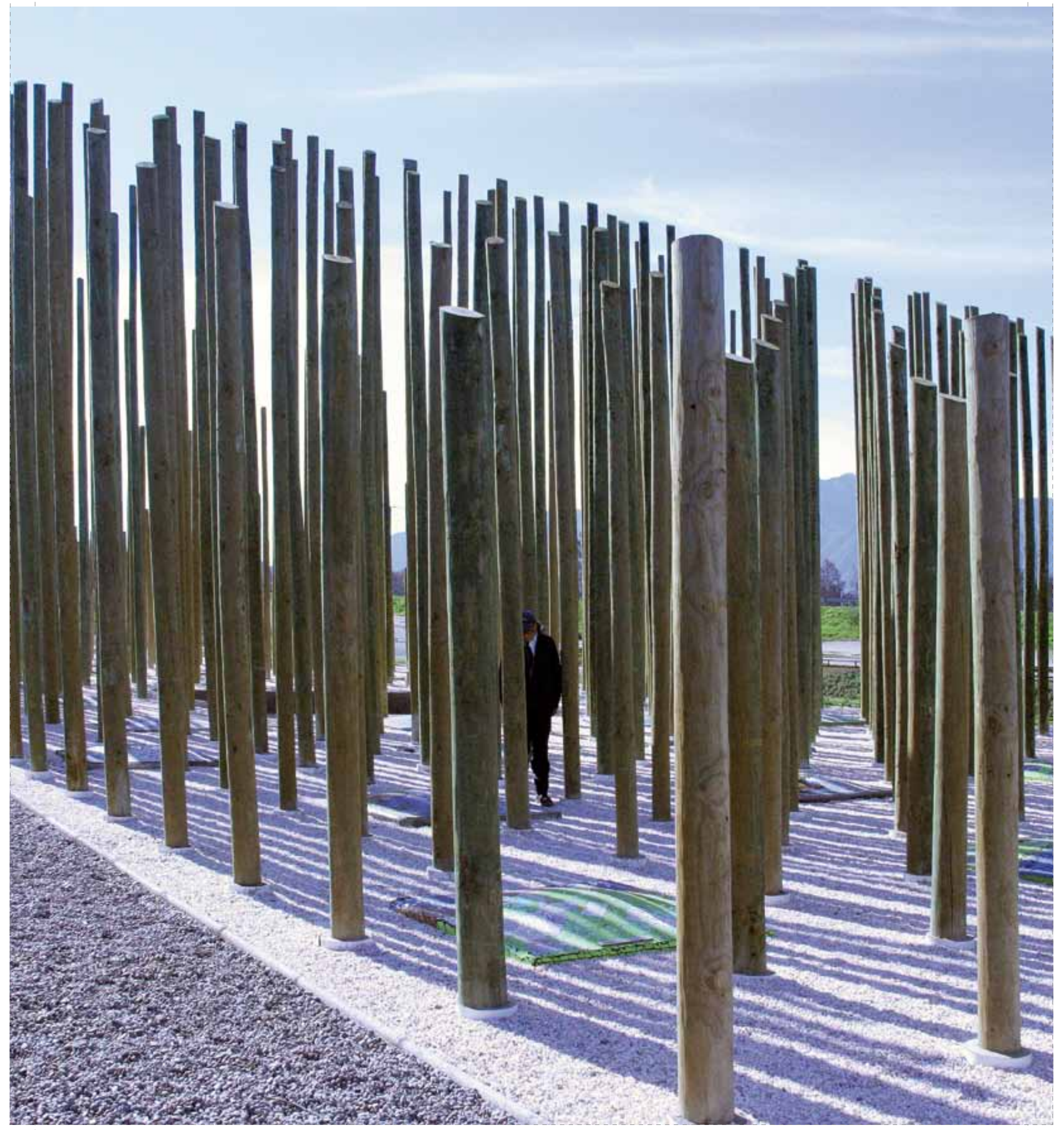




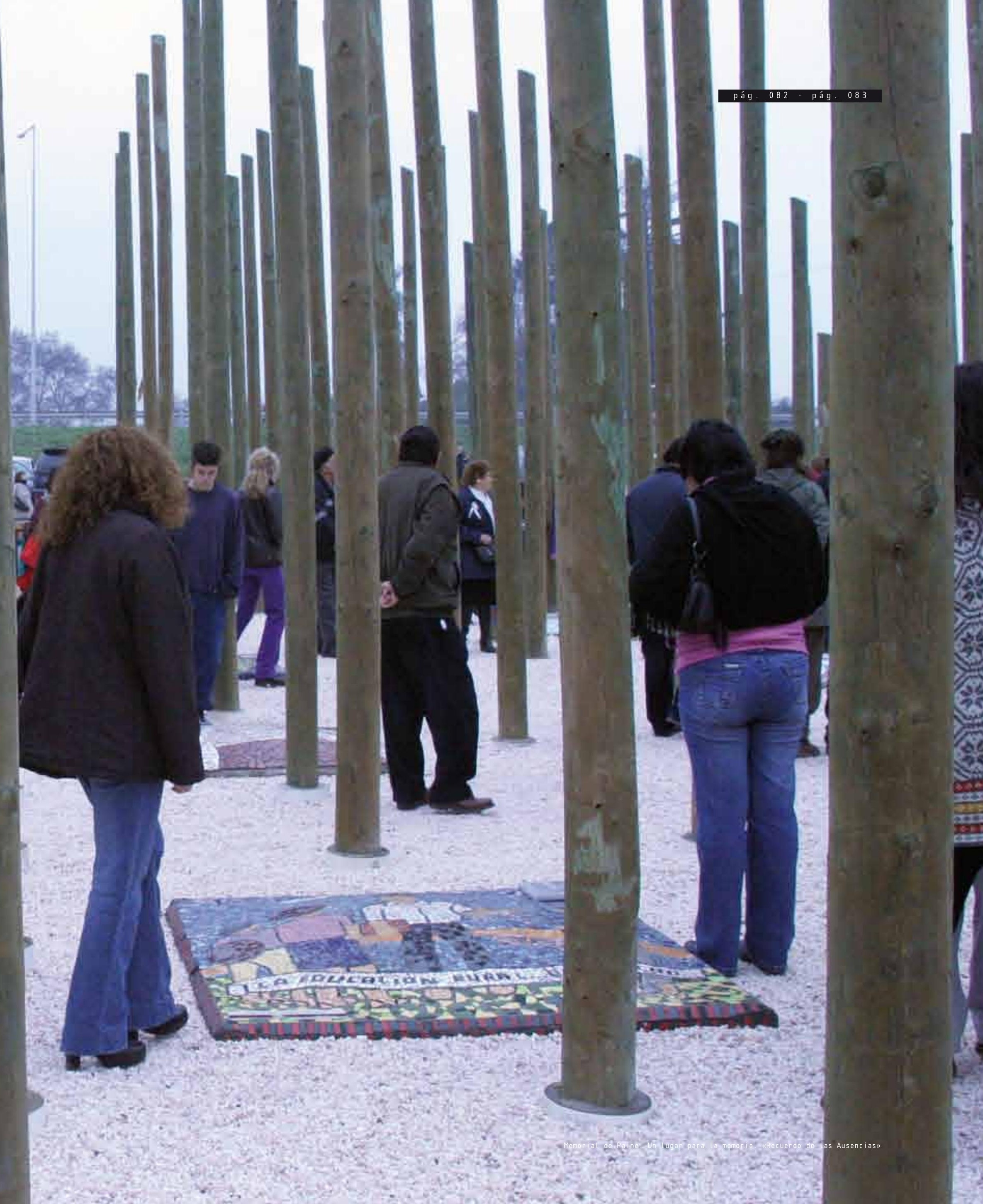

